\title{
A Pilot Study to Inform the Design of a Supportive Environment for Challenge-Based Collaboration
}

\author{
Galena Pisoni $^{1(\bowtie)}\left(\mathbb{D}\right.$ and Hannie Gijlers ${ }^{2}$ \\ 1 Department of Information Engineering and Computer Science, \\ University of Trento, via Sommarive 9, 38122 Trento, Italy \\ galena.pisoni@unitn.it \\ 2 University of Twente, Drienerlolaan 5, 7522 Enschede, NB, The Netherlands \\ a.h.gijlers@utwente.nl
}

\begin{abstract}
In the course "An introduction to FinTech: from mobile payments to blockchains", students are introduced to the broad area of FinTech, from both technical and business side. The course consists of two technical lectures that explain the students the basic technology for authentication and blockchain and two entrepreneurship lectures that discuss the fintech business ecosystem. In the rest of the course the students work on a project provided by companies in which they put into practice the obtained knowledge and provide a solution to a real life challenge. The course is face-to-face, with two weekly sessions of $2 \mathrm{~h}$ each. The students work in teams and each week they need to show progress/work towards the challenge resolution. The students are not constrained in any way and are asked to self organize for the team work. In this study we present the results we obtained from questionnaires that we delivered before the course on course expectations (that we used also to form the teams), during the course on teams' dynamics, and after the course to measure students' perception on collaboration strategies. We end the paper with a reflection on the design space for an application that can support this type of collaborative work online.
\end{abstract}

Keywords: Collaborative work $\cdot$ Team dynamics $\cdot$ Challenge-based education

\section{Introduction}

In order to meet the requirements of the 21st century labor market educational strategies need to adapt and focus more on strategies that promote self-regulated learning, problem solving and collaboration (teamwork). In the current paper we focus on teamwork in the context of solving authentic problems. Authentic problems presented by stakeholders form industry invite groups of students to demonstrate their knowledge and skills through the development of an innovative

(C) The Editor(s) (if applicable) and The Author(s), under exclusive license to Springer Nature Switzerland AG 2021

Z. Kubincová et al. (Eds.): MIS4TEL 2020, AISC 1236, pp. 216-225, 2021.

https://doi.org/10.1007/978-3-030-52287-2_22 
product addressing the presented problem. In this context students not only apply their knowledge and learn to deal with stakeholders within companies but they also develop their ability to operate in (multi) disciplinary teams. Challengebased education is an instructional approach that addresses the challenges of preparing university students for the 21st century labor market.

Challenge-based education is an alternative to traditional education in training engineering graduates to become independent learners, critical thinkers, problem solvers, lifelong learners as well as team players [10]. This educational model is relatively new, dates from around 2011, and it is built on problem-based learning, and it represents the next step forward. Challenge-based learning does not only require a problem as the center of the learning process, it also requires the challenge proposer to be involved as a stakeholder and to intensively cooperate with the students and guide them while they are working on the project. This approach facilitates students in developing practical competences through the resolution of a real business case $[10,15]$.

In challenge-based learning scenarios lecturers participate as mentors. They are in charge of the knowledge construction process and monitor the development of skills and competences. In such a context, the lecturers monitor the level of knowledge the learners gain during the learning process and at the same time make the students and challenge proposers collaborate with each other during the learning and work on the challenge. In challenged based education the methods of teaching and training as well as the specifics of the contents and tasks are constantly adapted based on the goals achieved by the students.

Teaching entrepreneurship is challenging due to its practical and experiential nature of the topic $[4,6,11]$. Entrepreneurship education is growing in popularity as it helps the transition from education to the labour market, and different initiatives aim at spreading entrepreneurship in the European higher education system $[11,20]$. However, key educational and didactic issues on how to implement entrepreneurship education adequately still remain open $[5,9]$.

Specifically tailored challenge-based courses in different entrepreneurship areas are starting to appear, with different possible course designs and course structure of such examples [21]. Still, besides all the advantages of the challengebased learning, there are actually little in our universities that implement it, and this paper showcases one example of how one such course.

Learning to work in teams is an important skill in today's (or modern) organizations and companies, because employees are often required to complete tasks and projects in flexible and multidisciplinary teams [1,2]. Although students can acquire important skills in teamwork and teamwork is positively associated with performance [14], grouping students in teams does not guarantee productive interaction [19].

Moreover, students' often have mixed feelings about teamwork [16]. Students expressing negative opinions about teamwork often refer to issues related to freeriding/unequal participation and issues related to receiving a grade as an entire team. Free-riding occurs when students do not contribute their fair share to the team. In situations where the process and students' individual efforts toward the 
overall team task are not taken into account in the assessment this is detrimental for students' attitude towards teamwork [7].

Furthermore, teams might experience difficulties reaching consensus, or dealing with diverse opinions and individual schedules. Research indicates that students' attitude towards teamwork, their beliefs in the effectiveness influence not only their willingness to cooperate with others [13] but also the outcomes of the team process [8]. However, if during a team assignment students have positive experiences like task-focused communication, and equal participation of the team members this positively influences their attitude towards future team assignments [17].

These findings stress that it is important to gain understanding of how students' attitudes and experiences develop over the course of a team activity, to ensure effective and satisfying team learning experiences. These insights can be used by educational designers and software developers to design adequate supportive measures, that allow for timely intervention when students experience problems.

Within the context of the current study we explore students expectations, experience with teamwork, as well as the reported difficulties after the completion of the task in the context of challenged-based team assignment. The results will be used to inform the design of an interactive learning environment or app that facilitates and supports effective team work in the challenge based education.

Our aim is to study team dynamics in students coursework, follow team work with standardized questionnaires, and from the experience draw conclusions about how to support teachers in following teams with different dynamics with a tool specifically designed for this. We contribute to the field by first exploring where difficulties in group work appear and then provide suggestions on how to track them in teams.

This paper is structured as follows: in Sect. 2 we present the method, the course setting and the participants, in Sect. 3 we present the results from the questionnaires as well as the perceptions regarding teamwork during the course work, as well as the observed challenges and benefits from the team work after the course as well as their impact on student learning and quality of the deliverables, in Sect. 4 we discuss design space for an application that can support this type of collaborative work online, and in Sect. 5 we conclude the paper and outline our next steps.

\section{Methods}

The approach we took to study team dynamics was the following: we first delivered an introductory questionnaire to understand better the starting expectations and motivations of the students towards the course and group work, later, during the course, we administered the midterm questionnaire, the aim was to track students perceptions of the activities, and at the end of the course we provided the final questionnaire to invite students to reflect on their participation in the group; for all of the three phases we relied on standardized questionnaires from the literature. 


\subsection{Participants}

Third year Bachelors students, and 1st and 2nd year Master school students from Innovation program, following the Financial Technology course, participated in the study. Students were assigned to teams of 4 or 5 , based on their responses on a questionnaire administered before the course, teams were formed consisting of students with a varying attitude towards teamwork. Due to the number of students that signed up and completed the course, the data from 25 participants were taken into account in our analysis. More specifically, the data originated from 6 teams, including 2 teams of 5 students, 3 teams of 4 students, and one team of 3 students.

\subsection{Cases}

Case 1. Pay with a Smile. Pay with a Smile (PwaS) aims to implement an evolutionary next step in the digital payments: develop a system that makes it possible to pay with biometrics (mainly face recognition, but later other methods are considered as well). PwaS doesn't require users to have a bank card or phone present. The payment is initiated by the merchant's device, face recognition is done by the back end system. PwaS aims for small retail stores (for frequent recurrent purchases) and tries to attract the widest audience possible. The students were asked to develop solutions around: i) the business model for the company (e.g. offered directly to merchants or use banks/acquirer companies as middlemen), ii) to come up with new use cases for use of biometrics and biometric identification in different scenarios, based in smooth interactions, and good user experience for final users, and iii) to suggest how services can preserve privacy and be GDPR-compliant. The teams were asked to choose between one of the three options of projects.

Case 2. mID 2.0. mID 2.0 is a new product (app) that securely stores identity credentials on smartphones. Depending on the security features of your smartphone hybrid storage is an option (e.g. partly cloud storage). With mID 2.0 users can use their smartphones as identity token/document. It replaces smartcards, tokens, documents... Service providers can securely verify the mID and provide access to services, e.g. a bank account, car rental, entry to a building. mID can be uses in face2face situations, human2machine or online. The students were asked to deliver: i) a reasonable business rationale for a bank to include mID 2.0 into a banking app, ii) to perform an analysis in terms of strengths, weaknesses, opportunities, treats in the European domain for a product like mID 2.0 and iii) to come up with a reasonable pricing model for a product like mID 2.0. Also in this case the students were asked to choose between one of the three options for projects.

\subsection{Questionnaires}

Three questionnaires were administered before participation in the team assignment expectations related to the team task were assessed, during the task 
students' perceptions about the collaborative learning processes and attitudes during the task were assessed, and after completion of the assignment students reflected on the challenges they experienced during the task. All questionnaires were administered using surveyhero (www.surveyhero.com) platform.

Introductory Questionnaire. Before the actual team work started students completed an adapted and contextualized version of the Students' Appraisal of group assignments questionnaire (SAGA), developed by [18]. Students completed the following six scales: 1) cognition, 2) motivation, 3) affect, 4) interpersonal, 5) team management and 6) group assessment. Students specified their level of agreement with each statement on a 4-point Likert scale (strongly disagree to strongly agree). An overview of the items in the questionnaire can be found in [18]. The alpha for the questionnaire as a whole reached .80 and Cronbach's alpha s of the subscales ranged between .44 and .79 .

Midterm Questionnaire. At the midterm we used a translated and adapted version of PCLA questionnaire, an overview of the items can be found in [12] to get a global understanding of the cooperation as it is perceived by the students during the collaboration. The questionnaire consisted of a total of 15 items (cronbach's alpha $=.82)$, 10 items addressing the group processes Cronbach's alpha $=.73)$ and 5 items addressing the attitude towards the attitude/perceived utility value (Cronbach's alpha $=.72$ ). Sample items included: "All group members participated actively" (group processes); "By working in a group on the assignment, I have learned more than I would have learned individually" (attitude). Cronbach's alpha for the questionnaire as a whole reached .82 .

End of Term Questionnaire. At the end of the course questionnaire was administered to gain understanding of the challenges individual team members were experiencing during the collaboration. Based on the work of [3] the questionnaire addressed the following four different aspects of the collaborative process: 1) Planning; 2) task execution; 3) progress monitoring; 4) and team functioning with respect to interaction and communication. For each of the four aspects challenges were formulated. An example of such a challenge for planning would be: We have different goals/standards for our work. A total of 22 challenges were presented to the students who had to report on a 5-point likert scale (from 1, not a problem to 5 , a very big problem) to what extent these challenges were a problem in their team. Cronbach's alpha for the questionnaire as a whole reached .95 . Items were recorded to make sure that high scores reflected a positive self-report.

\section{Results}

Mean scores on the SAGA questionnaires were compared with a Kruskall-Wallis test, results indicated no significant differences between teams on the test as a whole $(\mathrm{p}=.858)$, and the subscales cognitive $(\mathrm{p}=.311)$; motivation $(\mathrm{p}=.749)$; affect $(\mathrm{p}=.749)$; interpersonal $(\mathrm{p}=.738)$; team management $(\mathrm{p}=.850)$ and group assessment $(\mathrm{p}=.337)$. Indicating that on average teams did not differ in their expectations about the task (Fig. 1). 


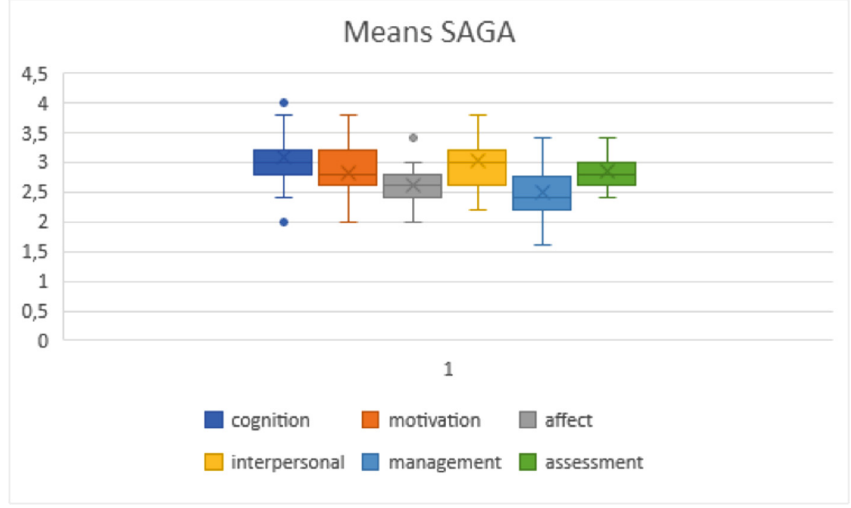

Fig. 1. The results from SAGA questionnaire.

The scale for the SAGA ranged between 1 and 4 , and overall we can see that the mean scores are fairly positive, above the midpoint of the scale. The results of a one way anova for within subjects effects shows that there was a significant effect of type of scale $\mathrm{F}(5,105)=10.88, \mathrm{p}=.00$. Suggesting that students responded differently to the subscales. The items that were lower rated seem to relate to the reported affect.

Follow up pairwise comparisons revealed that between most scales significant differences were found, but that the cognition scale did not differ significantly from the interpersonal scale, the motivational scale did not differ from the affective, interpersonal and assessment scale, the affective scale did not differ significantly from the team management scale and the interpersonal scale also did not differ significantly from the assessment scale.

During the execution of the task students completed the PCLA questionnaire. The results of a nonparametric independent sample Kruskal-Wallis test revealed no significant differences between teams on both the scale addressing the group processes $(\mathrm{p}=.232)$ and the attitude towards teamwork $(\mathrm{p}=.209)$

The end of the term questionnaire focussed on evaluation regarding the planning, task execution, progress monitoring and team functioning. The results of a Kruskall- Wallis test indicated significant differences between teams with respect to their scores on planning. Follow up analysis using Bonferroni corrections for multiple testing revealed that team 5 differed significantly from team 4 (adjusted $\mathrm{p}=.016$ ), the differences between the other teams were not significant. The differences between teams with respect task execution $(\mathrm{p}=.051)$ and progress monitoring $(\mathrm{p}=.057)$ are bordering significance. Again the highest means are observed in team 4 and the lowest in team 5. Suggesting that team 4 evaluated the team task positively compared to team 5 .

The results of the end of term questionnaire showed that team 5 reported difficulties related to different ideas about the standards for their work, as well as how they should work together. They also indicate problems with unmotivated team members, unequal participation, and report an unsupportive group climate (Table 1). 
Table 1. Mean ranks for the teams on each of the Subscales of the end of term questionnaire.

\begin{tabular}{|l|l|l|l|l|}
\hline Group & Planning & Task execution & Progress monitoring & Team functioning \\
\hline 1 & 10.75 & 10.12 & 12.75 & 11.25 \\
\hline 2 & 15.90 & 14 & 16.40 & 12.60 \\
\hline 3 & 9.25 & 10.75 & 10.12 & 15.50 \\
\hline 4 & 20.20 & 20.00 & 19.20 & 18.60 \\
\hline 5 & 2.67 & 3.50 & 3.50 & 3.00 \\
\hline 6 & 14.12 & 15.25 & 11.25 & 13.25 \\
\hline
\end{tabular}

Correlations between tests administered at the beginning, mid-term and end of term questionnaires were calculated. A positive and significant correlation between the reported group process at the midterm and the reported team functioning at the end term questionnaire was found $(\mathrm{r}=409, \mathrm{p}=.047)$.

Our impressions from the course confirmed the results obtained from the questionnaires, and it was indeed group 4 that was most cohesive, seemed to have best collaboration among the members and provided an in depth solution to the business challenge on several possible dimensions, whereas group 5 required most of the teachers attention, quite often requiring the teacher to intervene and to ask little proactive members to contribute to team work, or to send reminders to the whole team so that the team delivers the weekly deliverable together with the rest of the teams. The other groups performed sufficiently well and there was no need for any further teacher intervention in the group dynamics.

From our findings we can understand that the mid term questionnaire was most important for predicting the final outcomes of the team. As such we strongly suggest frequent administration of short questionnaires, most probably on a weekly basis. For future editions of the course that would be the aim, i.e to make it mandatory for each team to deliver the weekly submission and individually each team member to compile the questionnaire.

We next observed although many tools exist to help students to work together and assign tasks to members, a tools that allows teachers to monitor team dynamics and provide alerts when problematic dynamics occur or in general to allow for a teacher to have a comprehensive view on team dynamics over time doesn't exist, and in the next section based on our findings we draw guidelines for such tools.

\section{Discussion of Guidelines}

Designing task and assessment procedures that stress students' individual accountability and create a positive interdependence between students' can positively influence participation. However, for instructors it might be challenging to accurately assess the group processes. Software, supporting group work should 
address these challenges and provide features that not only support online collaboration and communication, but also increase students' awareness about their own as well others part in the group task.

We discuss further design principles for software to support group work for challenge-based courses, based on our initial results.

Contrasting the most and least successful group suggests that in the successful group students were able to reach agreement on the division of work and the quality criteria standards that they wanted to obtain, in the least successful group problems arose related to these issues. Our results are inline with the results of other studies investigating collaborative learning.

Team formation support based on cognitive and interpersonal, affect and management, and assessment and interpersonal similarity (or distance) between students

In order to tackle these problems the proposed tool should support students from different backgrounds that might have different views on collaboration in meeting each other online. Based on the approach that we used in our pilot provided is with information that suggests that it is important to take into account the different motivation traits of the students, teams can be formed based on cognitive and interpersonal affect and management, and interpersonal similarity. This can be evaluated based on introductory administration of the SAGA questionnaire with a mandatory follow-up and in-person interaction.

Group process and attitude towards work traced all the time

In our case we had a short term course over a period of one month, which made it difficult to administer the PCLA questionnaire more than once. However, we already saw first differences between the successful and less successful groups emerging at the midterm point, suggesting that in intensive courses, it is possible to identify emerging difficulties after two week of collaboration. In longer courses it might be relevant to ask the students to fill in the questionnaire periodically, to trace process and attitude towards work in students and capture variations in the students and their attitudes towards the team work. This feature would help teachers substantially in obtaining insights about team dynamics and each member's attitude towards the team work. Moreover, periodical assessment informs the teachers also about the effect of intervening.

Students need to be supported in planning of activities and the tool should allow for easy task execution and progress monitoring

Students told us that for them it was difficult to plan the distributed activities and that it was difficult to follow the "status" of different tasks that they had assigned to each other. This was especially important for tasks that required previous tasks to be finished in order to start working on them. One of our suggestions is to allow the students to create and trace tasks as well as their status, to have the possibility to assign task to team member, and to have an overview of the whole process of work towards the challenge, i.e in which phase each task is. Such a view will make it easier also for the teacher and the challenge provider to trace the status of the work towards the challenge too. Students reported use of different tools that allow for collaborative work in order to make 
their coordination on the task easier: some of them reported to have used Google Docs and Google Sheets for sharing of ideas and data, Hangouts and Skype for audio and video calls, and Trello for task management and task coordination.

A complete solution should allow students tools for video audio communications, shared writing space and sharing of data documents. Next to all these functionalities, it is very important for good teams functioning and dynamics to be able to plan, prioritize and assign tasks, this will additionally help identifying the problems with free-riding and quality of work. The display should also represent which sub-tasks are input for other tasks, like a Gantt chart. In addition, the tool should introduce to the students the basics of good group work, and support them with suggestions on how to achieve this (for instance, how to deal with free-riders, etc.).

\section{Conclusions}

In this paper we presented the results from an exploratory study on a challengebased course regarding teamwork of the students, and provided recommendations and suggestions for a tool that can support team work for tracing project work during a course. It is assumed that this type of tool will enhance teamwork skills that are important to fully prepare graduates for the workplace.

Although the number of participants is small and results have to be interpreted with caution, the data provided us insights for the development of a tool. The experiment forced the students to coordinate and communicate often and highlighted aspects relevant pertinent to expectations, motivation, team dynamics and attitude important that need to be in place to have a successful implementation of a challenge-based course.

Future pilots are planned and foreseen with different challenge-based courses.

Acknowledgment. The authors would like to acknowledge and thank the companies (E-group and Innovalor) for their participation and all the students who took part in the course.

\section{References}

1. Buchta, K., Jakubiak, M., Skiert, M., Wilczewski, A.: The analysis of students' expectations as a marketing challenge of a modern university. Przedsiskobiorczo i Zarzdzanie 20(6, cz. 2 Zmiany w myśleniu marketingowym), 41-51 (2019)

2. Cappelli, P., Keller, J.R.: Classifying work in the new economy. Acad. Manag. Rev. 38(4), 575-596 (2013)

3. Hadwin, A.F., Bakhtiar, A., Miller, M.: Challenges in online collaboration: effects of scripting shared task perceptions. Int. J. Comput. Support. Collab. Learn. 13(3), 301-329 (2018)

4. Halberstadt, J., Schank, C., Euler, M., Harms, R.: Learning sustainability entrepreneurship by doing: providing a lecturer-oriented service learning framework. Sustainability 11(5), 1217 (2019) 
5. Jakubiak, M., Buchta, K.: Determinants of entrepreneurial attitudes in relation to students of economics and non-economics. Studia i Materiały $(2 / 2016$ (21), cz. 1), 17-30 (2016)

6. Jie, S., Harms, R.: Cross-cultural competences and international entre preneurial intention: A study on entrepreneurship education. Educ. Res. Int. 2017 (2017)

7. Le, H., Janssen, J., Wubbels, T.: Collaborative learning practices: teacher and student perceived obstacles to effective student collaboration. Cambridge J. Educ. 48(1), 103-122 (2018)

8. Lembke, S., Wilson, M.G.: Putting the "team" into teamwork: alternative theoretical contributions for contemporary management practice. Hum. Relat. 51(7), 927-944 (1998)

9. León, G., Tejero, A., Dévora, N., Pau, I.: University as a platform: an evolutionary process towards an open educational ecosystem in Europe (2020)

10. Malmqvist, J., Rådberg, K.K., Lundqvist, U.: Comparative analysis of challengebased learning experiences. In: Proceedings of the 11th International CDIO Conference, Chengdu University of Information Technology, Chengdu, Sichuan, PR China (2015)

11. Maresch, D., Harms, R., Kailer, N., Wimmer-Wurm, B.: The impact of entrepreneurship education on the entrepreneurial intention of students in science and engineering versus business studies university programs. Technol. Forecast. Soc. Chang. 104, 172-179 (2016)

12. Mouw, J., Saab, N., Pat-El, R., van den Broek, P.: Student-and task-related predictors of primary-school students' perceptions of cooperative learning activities. Pedagogische Studiën 96(2), 98-122 (2019)

13. Rudawska, A., et al.: Students' team project experiences and their attitudes towards teamwork. J. Manag. Busi. Adm. Central Europe 25(1), 78-97 (2017)

14. Stump, G.S., Hilpert, J.C., Husman, J., Chung, W.t., Kim, W.: Collaborative learning in engineering students: gender and achievement. J. Eng. Educ. 100(3), 475-497 (2011)

15. Tejero, A., Pau, I., León, G.: Analysis of the dynamism in university-driven innovation ecosystems through the assessment of entrepreneurship role. IEEE Access 7, 89869-89885 (2019)

16. Thompson, D., Anitsal, I., Barrett, H.: Attitudes toward teamwork in higher education: a comparative study of religiously affiliated universities and secular-based universities. In: Proceedings of the Academy of Educational Leadership, vol. 13, Citeseer (2008)

17. Ulloa, B.C.R., Adams, S.G.: Attitude toward teamwork and effective teaming. Team Performance Manag. 10(7-8), 145-151 (2004)

18. Volet, S.: Significance of cultural and motivation variables on students' attitudes towards group work. In: Student Motivation, pp. 309-333. Springer (2001)

19. Volet, S., Vauras, M., Salo, A.E., Khosa, D.: Individual contributions in studentled collaborative learning: Insights from two analytical approaches to explain the quality of group outcome. Learn. Individ. Differ. 53, 79-92 (2017)

20. Żur, A.: Changing entrepreneurship learning ecosystems: Massive open online courses. opportunities and limitations. Przedsikebiorczo-Edukacja 14, 473-482 (2018)

21. Żur, A.: Two heads are better than one-entrepreneurial continuous learning through massive open online courses. Educ. Sci. 10(3), 62 (2020) 